\title{
Human at risk: Becoming human and the dynamics of extended sociality
}

\section{Jon Henrik Ziegler Remme}

\section{Introduction}

The question of what a human is seems to have become increasingly transformed in anthropological theorizing recently. Several empirically based debates within the discipline revolve around how the people we study conceptualize human beings and how they enact themselves and others as humans. This is of course closely connected to the concept of personhood, and as recent theorizations of animism (Willerslev 2007; Remme 2012), perspectivism (Viveiros de Castro 1998), actor-network theory (Latour 2007) and material semiotics (Law 2009) have shown us, personhood can be extended to various other forms of entities, including things, animals and other animate beings, creating thus variations over what Anna Tsing (2013) has termed 'more-than-human sociality'. Questioning what a human is within different ontological figurations, these approaches all point towards a concept of human being which is not pre-defined, confined by bodily boundaries or pre-relationally demarcated, but rather an entity that is always and already entangled with the nonhuman. As the contributions to this volume evidence, the forms these entanglements take and the processes through which they are enacted vary considerably, both in terms of what elements are held to be involved in the entangling and what role they play in it.

Although, as indicated in the introduction to this volume, the current climate crisis and the associated notion of the Anthropocene are sources of the attention to and radical rethinking of the human condition, including its involvement and entanglement with the nonhuman, the questions of what actually constitutes the human condition and how humans 
relate to the nonhuman are by no means new as topics of philosophical debate. In philosophy and theology, it has been a perennial problem how to account for the human, particularly as it relates to and distinguishes itself from the nonhuman. For instance, in his book The Open: Man and animal (2004), Agamben refers to a Hebrew Bible from the thirteenth century in which is depicted the messianic banquet of the last day. Here, at the conclusion of history, humans are depicted with their normal human bodies but also with animal heads, thus indicating that at the last day, the righteous humans will be reconciled with their animal nature (2004: 3). This should not be understood to suggest that animality is somehow human being's essence. Far from it, what is depicted here is not a total return to an animal state, but a reconciliation of two different life forms within a single entity.

This bodily image of the human and its metamorphosis in the last days is quite different from what we find in Heidegger's phenomenological philosophy, in which there is a qualitative difference between animal-being and human being-in-the-world, the latter being a fundamentally world-forming mode of being (Agamben 2004: 49-56). Despite these differences, in both views, human being in its proper form is separated from the nonhuman. Both accounts of human being operate thus upon a dualism, which in Heidegger's case is an ontological difference, while in the Hebrew Bible imagery, the dualism is maintained through its relational reconciliation.

The French-Russian philosopher Alexandre Kojève, which through his reading of Hegel saw this dualism, however, not as one between humans and nonhumans, but rather as a tension inherent within man himself, that is, as the mode of existence of humans. According to Kojéve, as expounded by Agamben, '[m]an exists historically only in this tension; he can be human only to the degree that he transcends and transforms the anthropophorous animal which supports him, and only because, through the action of negation, he is capable of mastering, and eventually, destroying his own animality' (2004: 12). 
What is particularly interesting with Kojève's concept of man is the way he relocates human being to practices concerned with managing the tension created by the metamorphic potential inherent within man himself. For Agamben, the re-location of humans within this tension means that instead of thinking humans as a conjunction of body and soul, or life and logos, biology and the social, we must learn to think of humans as what results from the incongruity of these elements. An investigation of the human condition, he suggests, must therefore not concern the metaphysical mystery of conjunction, but rather the practical and political mystery of separation, the 'mysterium disiunctionis' (Agamben 2004: 16).

I find these ideas of the human condition as located in a dialectical tension between human and nonhuman particularly interesting since, as we shall see, they speak to the processes of becoming and remaining humans that I find to be operative in the relational practices of the people with whom I have conducted fieldwork, the Ifugao of Northern Luzon, the Philippines. As in many other animistic societies in Southeast Asia, the ethnography of the Ifugao evidences clearly that '[h] umanity itself is an emergent condition' and 'a conditional quality that may be lost or removed by ritual means' (Århem in press: 6; Praet 2013). However, the conditions for becoming and remaining human require enacting relations with others in proper ways, be it other humans or other other-than-human beings, and although this relating often involves hard-earned differentiations from these others - the Ifugao mysterium disiuntionis - I show that the Ifugao ways of becoming human is not most essentially about disjunction but about a dynamic fluctuation between disjunction and conjunction. The 'mystery of disjunction' is thus but an aspect of a more general 'mystery of dynamics' between these two ontological conditions. Furthermore, I take this insight to bear on the notion of extended sociality and show that although there are many examples of Ifugao sociality that extends beyond human relations, their extended sociality is one that is highly dynamic and shifting. The dialectical tension within human being is not one that can be held 
still, but one that needs to fluctuate and transform. Basically, to become and remain human necessitates both separating from nonhuman others and occasionally dissolving that separation. The metamorphic potential of human being in Ifugao ontological dynamics entails that such conjunctions involves putting one's own human becoming at risk. But at the same time, the source of human life emerges from exposing oneself to one's own inherent transformability. This means that the extended sociality - in the sense of a sociality that includes both humans and nonhumans - must be partial and proportional, that is, it needs to be realized in shifting proportions, never in its totality and never in its annulment.

\section{The continuity of life and the plurality of life forms}

The Ifugao inhabit the precipitous Cordillera Mountains in the northern part of the Luzon, the Philippines. The villagers with whom I have conducted the majority of my fieldwork are farmers who combine wet rice cultivation in irrigated rice terraces with swidden gardens from which they harvest sweet potatoes, vegetables and fruits. The villages consist of house clusters of between ten and forty or more houses scattered in between rice terraces, along paths and ridges. Some of the villagers supplement their agricultural income with occasional wage labour periods in the lowlands or in the highland centre town of Baguio. The forests surrounding the villages are occasionally visited for gathering firewood or trees for building materials, but little hunting is nowadays done in them. Most households keep a dog and some chickens, and some hold pigs that are used primarily for ritual occasions. The close, almost family-like, relations people cultivate with their domestic animals, particularly pigs (Remme 2014), and the fact that omen animals such as birds, lizards, snakes, river frogs and crabs are spirits or closely associated with them (Béguet 2012: 268) indicate that all of these animals can be included within a more-than-human sociality. However, this sociality extends also further to include the spiritual beings who generically are called $b \bar{a} ' i$. These form a variegated category of beings that includes both ancestors (nun'apuh), a group of invisible 
beings called pinādeng who inhabit large stones, trees, rivers and other specific places in and around the village, as well as myriads of named invisible persons who are associated with celestial and meteorological phenomena or who have specific abilities to protect, guard, heal and inflict illness.

These different life forms differ from each other by the fact that they have different bodies. They behave differently because of their bodily differences, and in that respect, the bodies they inhabit are more than distinctive substances, they also entail 'an assemblage of affects or ways of being that constitute a habitus' (Viveiros de Castro 1998: 478). As in many other societies in Southeast Asia, for instance the Chewong (Howell 1989, 2014), Bentian (Sillander in press), and many Amerindian societies (Viveiros de Castro 1998), the difference in life forms entail differences in perspectives. However, while in Amerindian perspectivism the main differentiation of perspectives is that between humans and animals, Ifugao animism exemplifies what Århem has claimed is particular to Southeast Asian forms of perspectivism, namely that the differentiation and exchange of perspectives is primarily between humans and spirits (in press: 19). In Ifugao, both humans and $b \bar{a} ' i$ see the world in a recognizable human way, although the worlds that they see are different, often appearing as inversions of each other (Cederroth in press; Kaartinen in press; Janowski in press). These perspectival differences are, however, neither static nor total. Humans and $b \bar{a} ' i$ may see different worlds at most times, but the boundaries between these perspectives are both traversable and shifting. Humans may occasionally see the world according to the perspective of the $b \bar{a}$ ' $i$, a highly dangerous situation.

Despite the bodily and perspectival differences between the different life forms, they have in common a quality that is defining of life as such. This is the lennāwa, which in Newell's Ifugao dictionary is defined as 'the soul or spirit of a person or thing' (1993: 354), but which I would argue also refers, as do similar terms throughout the region like the 
Chewong ruwai (Howell 1989), Kelabit lalud (Janowski in press) and the Malay semangat (Endicott 1970), to a more pervasive life force held by all living entities. The ambiguity of this concept is clearly identified by Howell who points out that ruwai is (i) a vital principle and a prerequisite for life, (ii) consciousness and an ability to act according to rational principles, and (iii) a spirit-guide, or a familiar (Howell 1989: 127-141). The Ifugao lennāwa shares these characteristics with the Chewong ruwai, although the second and third meaning of the terms are highly contextual, being realized only in certain situations. A bird, for instance, is not accorded consciousness and ability for rational action at all times, but only when it appears to act strangely, as for instance when it enters into a house.

Lennāwa as a vital principle entails that there is continuity between all life forms. Human beings, animals, even in some cases plants, and $b \bar{a}^{\prime} i$ can thus participate in a common or extended sociality that potentially suffuses everything. This is the background for Barton's claim that ' $[t]$ here is little of importance that the Ifugao knows about, under his sun or under his earth or at the corners of his earth, that he has not deified' (1946: 11). The distribution of the lennāwa to all life forms combined with its reference to some sort of consciousness and intentionality, imply that there is a continuity of sociality between these life forms. It extends potentially across species boundaries and ontological divides.

However, such an extension of sociality to all living entities, or what Pedersen has referred to as a 'total socialization of the world' (2001: 415), is rarely realized everywhere and at all times. The total socialization operates rather as indicated above, as a potential in the sense that all living entities can be included in the sociality in which humans are embedded. Their actual inclusion is an effect of circumstances and is contingent on practice. Entities move in and out of this extended sociality thus making the latter a highly changeable and never fixed set of actualized relations. It will appear that it is exactly in the changeable forms of extended sociality that the generative source of human life is located. 
Hence, although humans, animals, plants, and $b \bar{a}$ ' $i$ share the quality of having a lennāwa, their bodily differences entails different perspectives. However, these perspectival differences are not static. Quite the contrary, the attachment of a lennāwa to a body is quite slippery, and this slipperiness entails that there is an inherent potential for metamorphosis into other life forms (Viveiros de Castro 2004; Béguet 2012; Howell in press). $B \bar{a} ’ i$ are invisible for humans in most everyday life, but on occasions they may metamorphose into different bodily forms. They can take on the body of an animal, as for instance a bird or a snake. They may also appear in a human-like body as the for adults invisible playmates of children or as humans with some sort of inverted characters, either mentally or physically. My adoptive mother related one example of this. She told me how a female neighbour of hers had been trapped into marrying a pinādeng. The pinādeng had visited the family to ask her parents for permission to marrying her and had then appeared in human form. As is customary after agreeing on marriage, the proposer had given the girl's family a number of pigs, and when they eventually got the pigs, they soon realized that they were not domestic pigs, but wild pigs, which are owned by the pinädeng. The pinādeng had thus metamorphosed into a human body, but the pigs that he brought, were the inversions of human domestic pigs and this disclosed his character. As the family had accepted the marriage through receiving the pigs, the girl had to remain married to the pinādeng. He had taken her to his village inside a mountain and lived with her there. For the parents, his marriage appeared as the illness and death of their girl. The lennāwa had left her body and she had become a $b \bar{a}$ ' $i$, separated from their domain and disjunct from the body and bones that they buried in their burial cave.

As this story shows, just as $b \bar{a} ' i$ have a metamorphic potential to become human, humans may become other-than-human (Béguet 2012; Howell in press). For humans this metamorphic potential mostly involves becoming metamorphosed into $b \bar{a}$ ' $i$, although myths 
abound with stories about how humans become trees, animals and plants too. The metamorphosis of humans into an other-than-human condition is set in motion when people dream and when they get ill. Both illness and dreaming are results of the temporary separation of lennāwa from the body. When the lennāwa is released from the body in dreaming, one is able to encounter other lennāwa, both those of the dead and the living. Such encounters, especially if they are repeatedly experienced, are potentially dangerous as they are ways in which the $b \bar{a} ' i$ attempt to lure with them the lennāwa of the sleeper, similar to what happened in the pinādeng marriage mentioned above. If the $b \bar{a} ' i$ succeeds in that, the sleeper will get ill and eventually experience bodily pain, grow thinner and weaker, in many cases loose reproductive abilities and eventually die. Both illness and dreaming are then partly realizations of the metamorphic potential inherent within the human life form, a potential to become $b \bar{a}$ ' $i$. Death is the ultimate realization of that potential. When humans die, their lennāwa becomes separated from their bodies on a more permanent basis. The lennāwa continues to live and will hang on to his former abode and attempt to stay in touch with the bereaved spouse and relatives. With time and after an exhumation ritual in which the lennāwa of the deceased is told to leave, the deceased is transformed in a nun'apuh, a proper ancestor spirit (see Couderc and Sillander 2012).

To avoid being contacted by the nun'apuh and thus to enact the nun'apuh as such, the spouse and relatives have to make sure that the burial cave is dry, clean and in proper condition and elsewise show their respect to the deceased and other ancestors. Basically this means that they must cultivate the rice terraces as their ancestors did and abide by the regulations laid down by a whole array of different 'cosmo-rules' (Howell in press). A case that is particularly instructive regarding this was the death of a man in the village who had behaved in ways others found contrary to what was expected by his ancestors. The man owned some rice terraces that had been destroyed in a landslide. He and I tried to rebuild the 
terraces, but we never managed to finish the work. I lacked the skills required for building stonewalls, and the man was in need of money and therefore rather spent his time pursuing that. Instead of repairing his terraces so that he could continue cultivating them as his ancestors had done, he dressed up in a traditional loin-cloth and a spear, walked up to the spot where tourists came to view the spectacular rice terraces and posed - for money - for the tourists wanting to take pictures of what many of them referred to as a 'true native'. After having done so for some months and leaving his terraces unrepaired, other villagers reacted without surprise when his already painful life - he suffered from some sort of rheumatic condition - took a turn for the worse. He was taken to hospital, but his life could not be saved, and he was eventually taken back to his village to die. According to most of the villagers I talked to, the reason for the illness and death was clear. The man had not behaved according to the will of the ancestors. He had shown disrespect for their way of living and had not maintained the terraces they once build. His ancestors had surely become angry with him, and made him ill. By misbehaving, the man had brought about his own demise, and now he would eventually turn into a nun'apuh himself.

As the above exposition makes clear, close contact between human beings and $b \bar{a}$ ' $i$ is potentially dangerous for humans as they risk becoming ill, die and then be metamorphosed into $b \bar{a}$ ' $i$ themselves. Because of this, the world of the humans and the world of the $b \bar{a}$ ' $i$ should mostly remain separate. The potential for total socialization must remain only a potential.

There are several techniques for ensuring that such separation is upheld. As indicated above, observing the rules for conduct, behaving according to the ways of the ancestors, maintaining rice terraces and keeping burial caves dry and clean are ways in which this separation is maintained. Also more specific practices can contribute to such separations, and these practices often take the form of sensorial manipulations. As in many other cases of 
perspectivism (for instance Viveiros de Castro 1998; Howell 1989), visibility is a crucial sensorial differentiator between humans and spirits. They see a different world. But perspectivism in its Ifugao form is highly multisensorial, drawing on an interplay of different senses, particularly the olfactory (Bubandt 1998; Telle 2003) and auditory senses. For instance, carrying a piece of ginger while visiting other villages will engulf the carrier in an olfactory protective shield, thus inhibiting potentially malevolent $b \bar{a}{ }^{\prime} i$ to smell him or her as a human. Likewise, by draping a particular plant around one's ear, one can hinder hearing the $b \bar{a} ' i$ talking to one and thus obstruct any auditory intervention by them.

While such techniques are crucial for enacting separation between humans and $b \bar{a}{ }^{\prime} i$ and thereby avoiding illness and death, such a separation can only be partial and temporary. The health and well-being of humans is to a large extent controlled by the $b \bar{a} ' i$. This operates on many levels and takes a variety of forms. On a direct level, the $b \bar{a}$ ' $i$ can, as mentioned, inflict illness to humans and kill them. Some $b \bar{a}$ ' $i$ have the ability to cause specific illnesses as their prime quality, as for instance the umaladang, those who inflict dysentery (Barton 1946: 62). Others do this by, as indicated above, effecting a separation of the lennawwa of the humans from their body, by luring it with them or marrying it. On a more indirect level, the $b \bar{a} ' i$ control the life and well-being of humans by controlling the yields of the rice terraces and results of hunting.

The Ifugao are known regionally and nationally for their extensive system of irrigated terraces. Entire mountainsides are carved into terraces, mostly upheld by stonewalls up to twenty meters high. In these terraces, they cultivate wet-rice of various sorts, most of which are for eating while a not insignificant part of the harvest is of a glutinous variant used for making rice wine. The cultivation of the terraces is lead by an agricultural leader called tomona' who will initiate the phases of planting and harvesting. After one day in which all work in the fields is tabooed, the rest of the villagers will follow suit, thus enabling the 
synchronization of the rice cultivation. The synchronization is vital for the result, as it will minimize pests, insect and bird attacks on the rice. In addition, the synchronization is an effect of a particular relation between the village and the $b \bar{a}^{\prime} i$. When the tomona' begins planting his fields, he will sacrifice chickens in them, and so will the rest of the villagers in theirs. After all the rice fields are planted, the village observe a three day celebration, ulpi. Then it is tabooed to walk through the fields and entrance into the village by outsiders is, if not totally forbidden, at least restricted by placing straws knotted into protective pudung knots at the main paths entering the village. When the fields are harvested, pigs are sacrificed and the blood sprinkled on statues of the rice $b \bar{a} ' i$ called Bulul, and when one starts eating the rice for the first time, a ritual should be held. Observing these taboos, regulations and ritual practices properly entail that relations with the $b \bar{a} ' i$ are enacted correctly, and this will ensure that lennāwa - in the sense of a general life force - flows from the $b \bar{a}$ ' $i$ and into the fields , resulting in fruitful harvests and general fecundity.

Also in the little hunting that my interlocutors did, enacting relations with the $b \bar{a} ' i$ was vital for success. The perspectival differences between $b \bar{a} ' i$ and humans entail that they see animals differently. For instance, what humans see as rats are for $b \bar{a}$ ' $i$ their chickens and the wild pigs that humans hunt in the forest, are for $b \bar{a}^{\prime} i$ their domestic pigs. If humans are to successfully hunt these pigs, they must first receive permission to take them by the $b \bar{a}$ ' $i$. As was often related by my interlocutors, even the most avid shooter's bullets or arrows would sweep past the target if the hunter has not performed the required ritual before venturing out into the forest.

Enacting relations with the $b \bar{a} ' i$ in a proper way is thus a prerequisite for the outcome of the agricultural and hunting efforts of humans. In this sense human life and reproduction rely on $b \bar{a}$ ' $i$. It is to be noted that this proper mode of relating does not entail a total and continuous separation with $b \bar{a} ' i$. But neither would a total integration make for continued life 
and reproduction. The continued existence of human beings requires that the separation must be temporarily overcome through an extended sociality that encompasses both humans and the $b \bar{a} ' i$. The most pronounced form of this and the arena in which this extended sociality is significantly modified, are the sacrificial rituals that accompany both efforts at healing and agricultural and hunting activities.

\section{Extending and contracting sociality through ritual}

Sacrificial rituals exemplify the extension and contraction of sociality in two major directions, one related to inter-human relations and the other to human-spirit relations. In both, sacrificial pigs are constitutively involved in the enactment of these relational processes (Remme 2014).

The sacrificial rituals differ slightly according to the purpose of the ritual as well as the rank of the family arranging it. In healing rituals, particular $b \bar{a} ' i$ are engaged with more than others, like for instance the umaladang or the specific nun'apuh causing the family problems as mentioned above, and agricultural rituals may contain the libation of blood on Bulul figures. The rank of the family within the local prestige hierarchy also accounts for ritual differences. The villagers are ranked in three prestige categories based on the size and quality of the rice terraces they own. The most prestigious families are entitled to invoke some $b \bar{a}$ ' $i$ that lesser prestigious families cannot, but the most notable difference is the number of pigs the family is expected to sacrifice in rituals. Although tied to rice terrace ownership, prestige must also be earned in practice, and this is one important way to do it. Poor families generally kill fewer and smaller pigs than the more wealthy, although this also varies with the seriousness of the illness. The prestige-generating effect of pig killings is conducive to the volatile character of ranking in this society. Hence, while based on rice terrace ownership, high rank could easily be lost if one cannot afford to buy enough pigs, and maintaining a status as a member the wealthiest adangyan rank is especially hard since that 
puts high demands on the number of pigs required. Sacrificing less than expected easily effectuates a loss of prestige, and conversely, a poor family who aspire for higher prestige and can afford to purchase more pigs than expected of them can increase their prestige.

These differences notwithstanding, all sacrificial rituals involve modifications of the scope of sociality's extension. One way in which this occurs is related to the distribution of pork that takes place when the sacrificial pigs have been killed. The pigs are cut into specific pieces, and the host family distribute these to kin on both the husband and wife's side. The recipients will redistribute the pork pieces further to their kin. The recipients are expected to reciprocate whenever they arrange or receive pork from a ritual. Kin relations are a central factor in choosing who should receive pork but not all kin receive pork at all rituals and a host family may choose to establish a meat exchange relation with non-kin family in order to build alliances with them and draw on their influence. In effect, distributing pork extends, as Munn has argued, 'the capacity to develop spatiotemporal relations that go beyond the self' (1986: 14). Being able to sacrifice more pigs than others, one extends one's network of relations. It is consequently through the realization of the capacity to extend spatiotemporal relations that 'actors produce their own value' (Munn 1986: 15), i.e. their prestige and influence. But these rituals may also involve the contraction of such relations. Prestigious families may not always have sufficient means to purchase the required number of pigs to uphold their meat distribution network. Moreover, some villagers have converted to Pentecostalism, and one way in which the converts enact their relations with God is through refusing to receive meat that has been in contact with the spirits. They thus obstruct the attempts at extending meat distribution relations.

The rituals are thus arenas for potential extensions and contractions of inter-human relations. In addition, through their temporary conjunction of humans and 
$b \bar{a}$ ' $i$ within the space-time of the ritual, the rituals evince a particular dynamic of extending and contracting sociality.

The rituals are lead by the mumbā'i who have undergone years of training and have been ritually authorized by the $b \bar{a}{ }^{\prime} i$ to officiate at rituals. The mumb $\bar{a}^{\prime} i$ begin the rituals by sitting inside the house of the family arranging the ritual - preferably in a traditional wooden one-roomed house built on stilts if the family owns one - while they invoke the names of the nun 'apuh of the family along with all the other $b \bar{a}$ ' $i$. The ability of the mumbā'i to remember numerous $b \bar{a}^{\prime} i$ is remarkable, but they acknowledge their limitations in this regard and make sure that invocation of each category of $b \bar{a}$ ' $i$ is followed by the phrase '....and all the others', thus ensuring that everyone is invited. The mumb $\bar{a}^{\prime} i$ tell them where to go and when they arrive they very briefly possess the $m u m b \bar{a}$ ' $i$ and are given a sip of the rice wine the family have brewed for the occasion. When all the $b \bar{a}^{\prime} i$ are held to have arrived, two chickens are killed and their bile sacs are inspected carefully. The size and colour of the bile sacs are channels through which the $b \bar{a}$ 'i speak, and through them they communicate their presence in the house as well as their acceptance or rejection of the ritual's continuation.

The mumbā'i eventually comes out of the house and repeat the invocations on the stone covered ground beneath the house door, and also there they are possessed by the $b \bar{a}$ ' $i$. The house yard is by then usually full of visitors who may be anyone since the rituals are basically open to everyone, but in practice visitors tend to be relatives, neighbours and friends of the family. Those who have shown up can now see the $b \bar{a}$ ' $i$ dance through the movements of the mumbā'i bodies. They can also hear them talk and converse with them, asking them why they contacted them and what they want. The $b \bar{a}$ ' $i$ respond through the whispering voices of the mumba' 'i. The mumbā'i dance and entice the $b \bar{a}$ ' $i$ over to the pigs that lie in the house yard, pigs that upon killing will have their lennāwa released from their 
flesh. The former is taken by the $b \bar{a}^{\prime} i$ while the latter is partly eaten by the human visitors to the ritual and partly distributed to the relatives of the family arranging it.

With these practices, the elsewise separation between humans and $b \bar{a} ' i$ is dissolved. They are all there. All the individually named $b \bar{a} ' i$ and 'all the others' are then in the human domain and specifically in that house and in that yard, and humans and $b \bar{a} ' i$ can engage in interaction like for instance chewing betel nuts together, drinking rice wine, talking and most importantly exchanging lennāwa. The extended sociality encompassing both humans and $b \bar{a}{ }^{\prime} i$ is thereby realized in its totality. Such a total realization of this extended sociality must be done in order to let the $b \bar{a}$ ' $i$ receive pigs and to let them take part in the feast, leaving some $b \bar{a}$ ' $i$ out would have detrimental consequences. This realization is, then, crucial for the reproduction of human life, agricultural fecundity and the continuation of becoming human.

However, for reasons pointed out above, this momentary realization of the extended sociality is potentially dangerous. While essential for human life and reproduction, too long and too close contact with the $b \bar{a}$ ' $i$ endangers human life. This means that the realization of the extended sociality must be controlled and only temporary, which accounts for the number of restrictions surrounding the ritual practices and the strict separation inducing taboos the participants must obey in the days after the ritual.

The regulations mentioned here concern both the spatial and temporal arrangement of the rituals as well as who are entitled to perform the various tasks of the ritual. Rituals like these should commence during night and should be accompanied by rice wine of good quality. It is only mumb $\bar{a}^{\prime} i$ who have been authorized by the $b \bar{a}$ ' $i$ who can officiate, anyone else would seriously impede the effect of the ritual and could in some cases cause death. The different categories of $b \bar{a}^{\prime} i$ must also be invoked in a specific order. One must, for instance, make sure to invoke the liblibāyan and bagawah before opening the jars of rice wine since these are the protectors of these jars. The $m u m b \bar{a}$ ' $i$ must also follow the regulations regarding 
spatial movement, beginning inside the house and move down the house ladder and repeat the invocations in the kolhoddan, the stone covered ground beneath the house door, an area in which the butchering of the pigs also must take place.

Towards the end of the ritual, the mumbä' $i$ move up again into the house and call the $b \bar{a} ' i$ to come with them. They there share a meal with them and tell them to leave the house and go back to their world. The mumbā' $i$ thus set in motion a re-separation of humans and $b \bar{a} ' i$, and this separation needs to be stabilized in the days that follow. This is done by taboos on practices that could attract the $b \bar{a}^{\prime} i$ again. Among the most important taboos to observe is the prohibition on eating strong smelling food such as citrus fruits and fish. These items are held to produce a smell that is similar to burned feathers and singed pig hair. During the rituals, the chickens are singed in the hearth before they have their bile sacs inspected and the pigs are singed with burning rice straws to enable their hair to easily scrape off. Both of these practices produce a smell that is particularly attractive to $b \bar{a} ' i$, and by tabooing this smell through prohibiting eating citrus fruits and fish, one ensures that the $b \bar{a} ' i$ are not tempted to come back for more.

Ifugao sacrificial rituals are thus ways in which the separation between humans and their other-than-human others is temporarily dissolved. They become thus for a while present within the same space-time, a situation which is both fruitful and dangerous. Moving in and out of this situation is crucial for life to continue and for the continued enactment of human life.

\section{Conclusion}

In a recent article regarding the ontology of Chewong animism, Signe Howell points out that their ontology is characterized by a seeming paradox. 'While everything is connected in an existential and, indeed, life-giving, manner, different beings, domains and objects of significance must be kept separate. Chewong relations with each other and with the 
multifarious forest environment are predicated upon these two principles of connectedness and separation which, I suggest, constitute the semantics of sociality' (in press: 59, my emphasis). The Chewong acknowledge the distribution of ruwai - the Chewong nearequivalent of the Ifugao lennāwa - to all sentient beings, and follow up this idea of connectedness by a rule declaring that food must be shared equally by all present. Eating alone, i.e. disregarding connectedness, will provoke attacks by other-than-human beings. This connectedness notwithstanding, 'each person, entity or element contains its own existence, its own domain and its own premises for social life which should not be disturbed or contaminated by interference from other worlds' (Howell in press: 64), and this is the reason for the overriding rule of keeping that which is different apart. Following these rules in practice will inhibit metamorphosis, keep the person within his body and thus maintain the existential identity of that person. Hence, it is through practice that reality is brought into being by each category of sentient being.

The paradox of the concomitant principles of connectedness and separation has much in common with the ontological dynamics I have explored above. The notion of lennāwa provides for a potential for connectedness between all animate beings, but the metamorphic potential that is accompanied by this continuity entails that for entities to become stabilized in their existential identity, for instance as humans, they must practice separation, especially from the $b \bar{a} ' i$. But as in Chewong, separation must somehow operate along with connectedness, and this aspect of Ifugao sociality is enacted explicitly in the sacrificial rituals. The stabilization of lennāwa and sustainment of human life requires momentary connectedness and thus exposure to one's potential metamorphic alterity or to put it otherwise, to that life form one may become, namely $b \bar{a}$ 'i. Humanness is thereby an effect of a continuous becoming that thrives on the risk of becoming otherwise. In one sense, then, Kojève was right in claiming that humans exist in the tension inherent within humans 
themselves between the human and the nonhuman. As my ethnography from Ifugao demonstrates, there is an emergent potential of remaining within the tension inherent in human becoming. It is here - in that tension - that humans become and become stabilized. It should be noted that, as several ethnographies from Southeast Asia demonstrate (see for instance Århem and Sprenger in press; Béguet 2012), this dynamic of human becoming through shifting extensions and contractions of sociality is far from idiosyncratic to Ifugao, but seems to be a more general pattern of Southeast Asian, and possibly other (Praet 2013), animisms.

Relations between humans and $b \bar{a} ' i$ are therefore neither characterized by an always and already shared sociality nor by a total social discontinuity. Rather, they form a relational field that is fundamentally transformative and which moves between different forms, and this movement, this transformation, is required in order to sustain humans in their human life form. The metamorphic potential of human life, its ability to transform into different life forms, entails that it emerges from a handling of this potential, of keeping it in check, and in a way holding human life within its own limits of transformation. Stabilization of human life thus demands practices that restrict life's metamorphic potential. And what is particularly striking here, is that this stabilization requires momentary potential destabilizations. Human life emerges thus from putting it to risk, because it is only by entering into a momentary dissolution of the separation of life forms that human life can be sustained.

The actual emergence of humans from such events depends on a number of factors. Most importantly here is that the rituals are performed according to the ways laid down by the ancestors and that taboos are observed in the days after the ritual. For the rituals to have effect, the required number of pigs must be sacrificed, the specific $b \bar{a}$ ' $i$ needed for the purpose of the ritual must be invited in the correct order, the $b \bar{a} ' i$ must be given rice wine with a correct colour, and the liver and bile sacs of sacrificed animals, both pigs and chickens, 
must have a promising shape and colour. In addition, the participants must not eat vegetables, fruits and fish for a specific number of days subsequent to the ritual, the number of days depending on how close kin relations one has to the family arranging the ritual. All this is needed to impede the inherent potential for metamorphosis of humans into a nonhuman life form, to deter humans from becoming $b \bar{a}$ ' $i$.

The ethnographic and analytical points I have made here speak directly to how sociality becomes extended to include entities beyond the human. As I have made clear, Ifugao sociality certainly extends beyond the confines of the human and includes also otherthan-human beings. But this extension is by no means stable and limitless. Rather, it is fluctuating, expanding and contracting according to circumstances. In some instances, that extension is forced upon humans, as when $b \bar{a}^{\prime} i$ metamorphose and make their presence known in the human domain, in other cases, humans enact that extension by will, as in sacrificial rituals. These different ways of extension are interrelated as the former necessitates the latter. In both cases, however, the extension must be followed up by contraction, that is, by re-establishing separations between humans and $b \bar{a}$ ' $i$. Human becoming emerges then from the proper enactment of a more-than-human sociality that moves between degrees of proximity and distance. As such, Ifugao more-than-human sociality is a shifting relational field or a constantly transforming 'proportional sociality’ (Jiménez 2008: 186; see Sprenger in press for a similar idea of 'graded personhood'). The movement between increasing and decreasing those proportions is the source of human becoming in Ifugao. That dynamic quality of the extended sociality provides ground for continued life in human form and at the same time 'allows for an on-going escape from the always lurking dangers of holistic totalization' (Willerslev and Pedersen 2010: 269). This means that in addition to acknowledging that sociality may be more-than-human we must pay attention to the dynamics of that extended sociality, to how it expands and contracts, how it emerges through 
the unfolding of shifting connections and through the collapse and rebuilding of ontological crevices.

\section{References}

Agamben, Giorgio 2004. The open: Man and animal. Stanford: Stanford University Press.

Århem, Kaj in press. 'Southeast Asian animism in context', in Århem, Kaj and Sprenger, Guido (eds.) Animism in Southeast Asia. London: Routledge, pp. 3-30.

Århem, Kaj and Guido Sprenger (eds.). in press. Animism in Southeast Asia. London: Routledge.

Barton, Roy Franklin 1946. 'The religion of the Ifugaos', American Anthropologist 48: 1-211.

Béguet, Véronique 2012. 'Iban petara as transformed ancestors', in Couderc, Pascal and Sillander, Kenneth (eds.) Ancestors in Borneo Societies: Death, Transformation, and Social Immortality. Copenhagen: NIAS Press, pp. 243-277.

Bubandt, Nils 1998. 'The odour of things: Smell and the cultural elaboration of disgust in Eastern Indonesia', Ethnos 63(1): 48-80.

Cadena, Marisol de la 2010. 'Indigenous cosmopolitics in the Andes: Conceptual reflections beyond "politics"', Cultural Anthropology 25: 334-370.

Cederroth, Sven in press. 'Gods and spirits in the wetu telu religion of Lombok', in Århem, Kaj and Sprenger, Guido (eds.) Animism in Southeast Asia. London: Routledge, pp. 236-256. 
Couderc, Pascal and Sillander, Kenneth 2012. 'Introduction', in Couderc, Pascal and Sillander, Kenneth (eds.) Ancestors in Borneo Societies: Death, Transformation, and Social Immortality. Copenhagen: NIAS Press, pp. 1-61.

Endicott, Kirk 1970. An Analysis of Malay Magic. Singapore: Oxford University Press.

Howell, Signe 1989. Society and cosmos: Chewong of peninsular Malaysia. Chicago: The University of Chicago Press.

Howell, Signe 2014. 'Metamorphosis and identity: Chewong animistic ontology', in Harvey, Graham (ed.) The Handbook of contemporary animism. New York: Routledge, pp. 101-112.

Howell, Signe in press. 'Seeing and knowing: Metamorphosis and the fragility of species in Chewong animistic ontology', in Århem, Kaj and Sprenger, Guido (eds.) Animism in Southeast Asia. London: Routledge, pp. 55-72.

Janowski, Monica in press. 'The dynamics of the cosmic conversation: Beliefs about spirits among the Kelabit and Penan of upper Baram river, Sarawak', in Århem, Kaj and Sprenger, Guido (eds.) Animism in Southeast Asia. London: Routledge, pp. 181-204.

Jiménez, Alberto Corsín 2008. 'Well-being in anthropological balance: Remarks on proportionality as political imagination', in Corsín Jiménez, Alberto (ed) Culture and wellbeing: Anthropological approaches to freedom and political ethics. London: Pluto Press, pp. 180-197. 
Kaartinen, Timo in press. 'Boundaries of humanity: Non-human others and animist ontology in Eastern Indonesia', in Århem, Kaj and Sprenger, Guido (eds.) Animism in Southeast Asia. London: Routledge, pp. 219-235.

Latour, Bruno 2007. Reassembling the social: An introduction to actor-network-theory. Oxford: Oxford University Press.

Law, John 2009. 'Actor network theory and material semiotics', in Turner, Bryan S (ed.) The new Blackwell companion to social theory. Oxford: Blackwell-Wiley, pp. 141-158.

Munn, Nancy D 1986. The Fame of Gawa: A Symbolic Study of Value Transformations in a Massim (Papua New Guinea) Society. Cambridge: Cambridge University Press.

Newell, Leonard E 1993. Batad Ifugao dictionary with ethnographic notes. Manila:

Linguistic Society of the Philippines.

Pedersen, Morten A 2001. 'Totemism, animism and North Asian indigenous ontologies', The Journal of the Royal Anthropological Institute 7: 411-427.

Praet, Istvan. 2013. 'Humanity and life as the perpetual maintenance of specific efforts: A reappraisal of animism'. In Ingold, Tim and Palsson, Gisli (eds.) Biosocial Becomings: Integrating Social and Biological Anthropology. Cambridge: Cambridge University Press, pp. 191-210.

Remme, Jon Henrik Ziegler 2012. Manifesting potentials: Animism and Pentecostalism in Ifugao, the Philippines. PhD dissertation, Department of Social Anthropology, Oslo: University of Oslo. 
Remme, Jon Henrik Ziegler 2014. Pigs and Persons in the Philippines: Human-Animal Entanglements in Ifugao Rituals. Lanham: Lexington Books.

Sprenger, Guido in press. 'Graded personhood: Human and non-human actors in the Southeast Asian uplands', in Århem, Kaj and Sprenger, Guido (eds.) Animism in Southeast Asia. London: Routledge, pp. 73-90.

Telle, Kari 2003. 'The smell of death: Theft, disgust and ritual practices in Central Lombok', in Kapferer, Bruce (ed.) Beyond Rationalism: Rethinking Magic, Witchcraft and Sorcery. New York: Berghahn Books, pp. 75-104.

Tsing, Anna 2013. 'More-than-human-sociality: A call for critical description', in Hastrup, Kirsten (ed.), Anthropology and nature. New York: Routledge, pp. 27-42.

Viveiros de Castro, Eduardo 1998. 'Cosmological deixis and amerindian perspectivism', The Journal of the Royal Anthropological Institute 4: 469-488.

Viveiros de Castro, Eduardo 2004. 'Exchanging perspectives: The transformation of objects into subjects in Amerindian ontologies', Common Knowledge 10: 463-484.

Viveiros de Castro, Eduardo 2012. 'Cosmological perspectivism in Amazonia and elsewhere', HAU 1: 45-168.

Willerslev, Rane 2007. Soul hunters: Hunting, animism, and personhood among the Siberian Yukaghirs. Berkeley: University of California Press.

Willerslev, Rane and Pedersen, Morten A 2010. 'Proportional holism: Joking the cosmos into the right shape in North Asia', in Otto, Ton and Bubandt, Nils (eds.) Experiments in Holism: 
theory and practice in contemporary anthropology. Chichester: Wiley-Blackwell, pp. 251261. 